\title{
Novel Nanocomposite Optical Plastics: Dispersion of Titanium in Polyacrylates
}

\section{Gunjan Suri, ${ }^{1}$ Mukti Tyagi, ${ }^{1}$ Geetha Seshadri, ${ }^{1}$ Gurcharan Lal Verma, ${ }^{2}$ and Rakesh Kumar Khandal ${ }^{1}$}

\author{
${ }^{1}$ Shriram Institute for Industrial Research, 19, University Road, Delhi 110007, India \\ ${ }^{2}$ Department of Chemistry, Delhi College of Engineering, Bawana Road, Delhi 110042, India
}

Correspondence should be addressed to Rakesh Kumar Khandal, rkhandal@shriraminstitute.org

Received 5 December 2009; Accepted 17 January 2010

Academic Editor: Apparao M. Rao

Copyright ( 2010 Gunjan Suri et al. This is an open access article distributed under the Creative Commons Attribution License, which permits unrestricted use, distribution, and reproduction in any medium, provided the original work is properly cited.

\begin{abstract}
Polyacrylates have become the preferred materials for optical applications replacing the conventionally used glass due to their superior optical clarity. The major disadvantage with polyacrylates is their low (1.40-1.50) refractive index besides their poor impact resistance. The improvements in refractive index as well as mechanical properties can be achieved by way of incorporation of metals or metal compounds in the matrix. A novel methodology for the incorporation of high refractive index metals into low refractive index polymeric materials to improve the refractive index and impact resistance of the latter has been developed. With the in-situ formation of nanoparticles of $\mathrm{TiO}_{2}$, the refractive index of polyacrylates improved from 1.45 to 1.53 and the Abbe number increased from 40 to 57. One of the interesting dimension of this study pertains to the possibility of tailor-making of the two key optical properties of materials by way of varying the amount of $\mathrm{TiO}_{2}$ being formed in-situ. Thermal stability and impact resistance of nano dispersed ( $4.3 \%$ by wt. of $\mathrm{Ti}$ ) polyacrylates are found to be better than the neat polyacrylates. Moreover, $\mathrm{TiO}_{2}$-containing polyacrylate is of light weight. TEM, SEM, and IR analysis confirms the in-situ formation of nanoparticles of $\mathrm{TiO}_{2}$. Gamma irradiation has been used as an eco-friendly technique for polymerization. The developed compositions can be cast polymerized into clear and bubble free material for optical applications.
\end{abstract}

\section{Introduction}

Amongst the conventional materials used for optical applications, glass has been the most popular and till recently considered as the preferred candidate material. Glass, besides being a brittle and heavy material, is also prone to scratches. Plastics with optical properties as good as glass, if not better, have been found to be a better material than glass for various optical applications [1-7].

Apart from being light weight, optical plastics exhibit optical properties like refractive index, Abbe number, and transmittance superior to glass. These days, it has become possible to maneuver all of these properties by designing suitable optical plastics. However, it has been a challenge to manufacture optical plastics with high refractive index and high Abbe number. The other big challenge pertaining to the development of optical plastics concerns the tailormaking of properties. It has not been possible so far to have chemistries that can produce materials of varying properties as per requirements. For this, composite materials in devices such as lenses, coatings and filters are being extensively studied [8-11]. Organic-inorganic composite materials are being considered as the potential candidates for optical devices due to their properties of improved hardness, high refractive index and high Abbe number. The inorganic component such as metals and metal salts provide physicomechanical properties to the matrix whereas the organic part or continuous phase such as plastics binds them together providing a uniform distribution of reinforced material, that is, metals. One of the approaches found [12] feasible and possible by the authors pertains to the in-situ synthesis and dispersion of nanoparticles of metals or metallic salts for the preparation of metal containing compositions. Incorporation of titanium in plastic matrices to form homogeneous and optically clear compositions was a challenge till recently. 


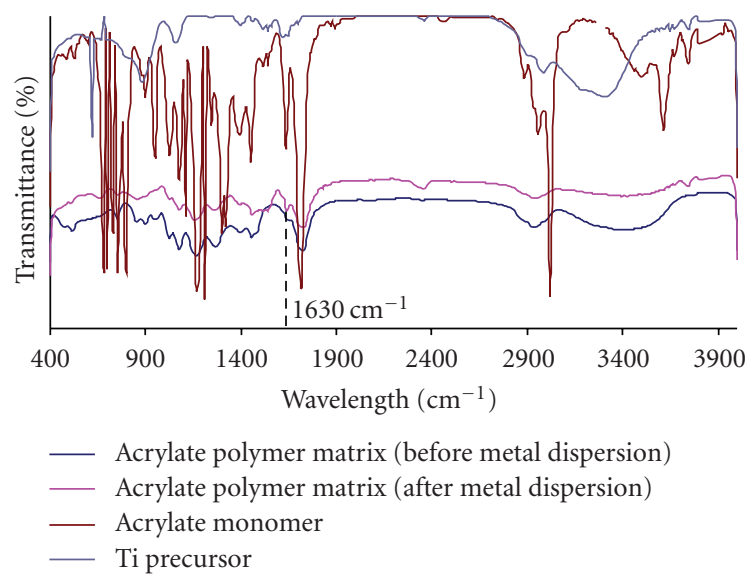

Figure 1: FTIR-Analysis of (a) Acrylate monomer, (b) Titanium precursor, (c) Acrylate polymer matrix (without metal dispersion), (d) Acrylate polymer matrix (with metal dispersion).

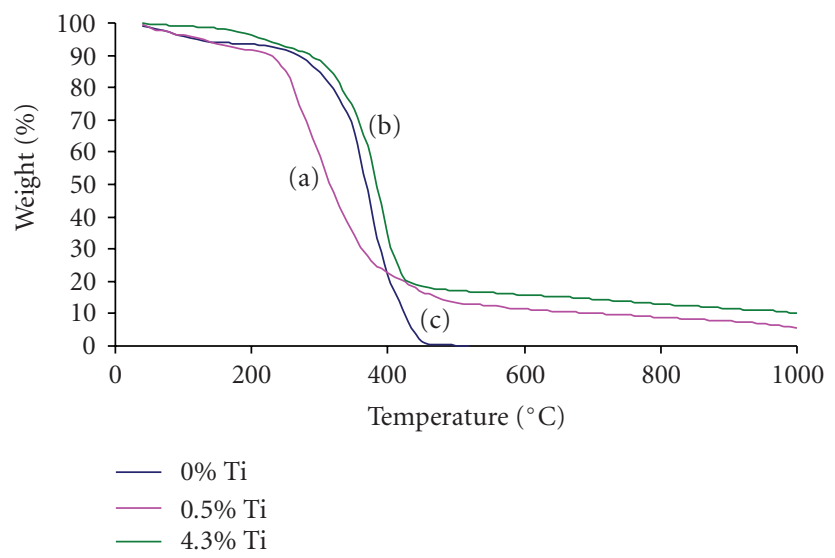

Figure 2: Thermogravimetric analysis of titanium containing nanocomposites and reference material.

Polyacrylates have been recognized as an obvious choice for optical applications, for example, spectacle lens [13]. The refractive index of polyacrylates is limited between 1.42 to 1.49 and to increase the refractive index further, dispersion of high refractive index metal compounds is one of the available options. The high refractive index and high hardness of titanium makes it a desirable metal for dispersion in optical plastics. It would be interesting to prepare high refractive index polymers based on acrylate as a base material.

In the present study, an attempt has been made to disperse titanium in different percentages in acrylate matrix and subsequently cast polymerized into lenses. Gamma radiation has been adopted for polymerization. By using gamma irradiation, the authors have been successful in creating a new range of acrylate polymers with unique features of high refractive index and high Abbe number.

\section{Materials and Methods}

2.1. Raw Materials. Acrylate monomer (99.9\%) was procured from ACROS Chemicals, USA. Titanium precursor of industrial grade was procured from a local source. All the raw materials were used as such without further purification.

\subsection{Methodology}

(a) Dispersion of Titanium. Titanium precursor was added to the hydroxy alkyl acrylate monomer under vigorous stirring at room temperature for the formation of nanoparticles. The maximum possible amount of titanium that can be dispersed without adversely affecting the optical clarity of the acrylate monomer was determined and studied further.

(b) Cast Polymerization. The compositions were degassed under vacuum and injected into glass molds fitted in a gasket. They were then cast polymerized into lenses using gamma irradiation at dose rate of $25 \mathrm{kGy} / 12 \mathrm{hrs}$.

\subsection{Characterization}

(1) FTIR Analysis. The metal containing polymers were evaluated by FTIR for structural elucidation. The FTIR Spectrophotometer FTIR-ATR BOMEM (FTLA 2000) in transmittance mode from $4000-400 \mathrm{~cm}^{-1}$ was used.

(2) Thermal Analysis. Thermogravimetric analysis (TGA) was performed using SDT 2960 of TA Waters Instruments, USA. TGA was used to measure the thermal stability of the metal containing acrylate and to evaluate the residue content. The studies were carried out in nitrogen atmosphere at a heating rate of $10^{\circ} \mathrm{C} / \mathrm{min}$, from room temperature to $1000^{\circ} \mathrm{C}$.

(3) Particle Size and Surface Morphology and Homogeneity. Transmission Electron Microscopy (TEM) was performed on Morgagni 268D to determine the dispersion and particle size of the nanoparticles in the polymer matrix.

Scanning Electron Microscopy (SEM) was performed on LEO $435 \mathrm{VP}$ to study the particle shape of the dispersed material and surface morphology of the polymer.

Homogeneity of the cast polymerized lenses were evaluated with Polariscope Model 243, PTC Instruments, USA for the presence of bubbles in the lenses.

(4) Refractive Index and Abbe Number. Atago Refractometer DRM4 was used to determine the refractive index and Abbe number of the titanium nanocomposites [14].

(5) Transmittance (\%). UV-Vis Spectrophotometer (Shimadzu 1700) was used to determine transmittance of the titanium containing polymer nanocomposites.

(6) Specific Gravity. Specific gravity of the polymer was determined as per ASTM D-792-00 [15]. 


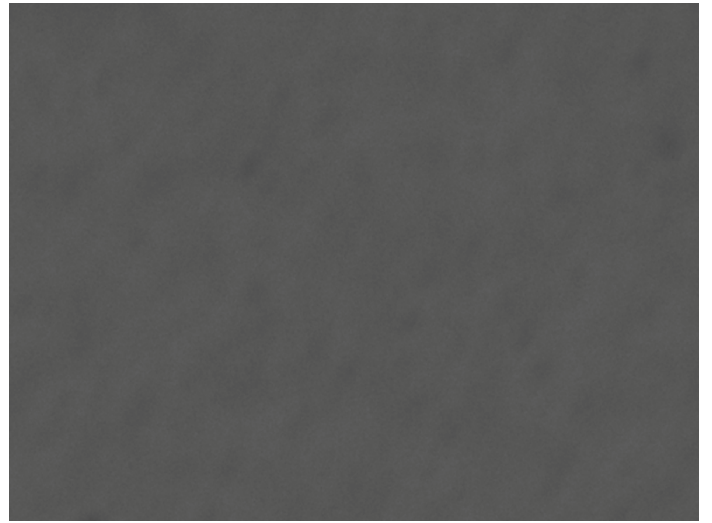

(a)

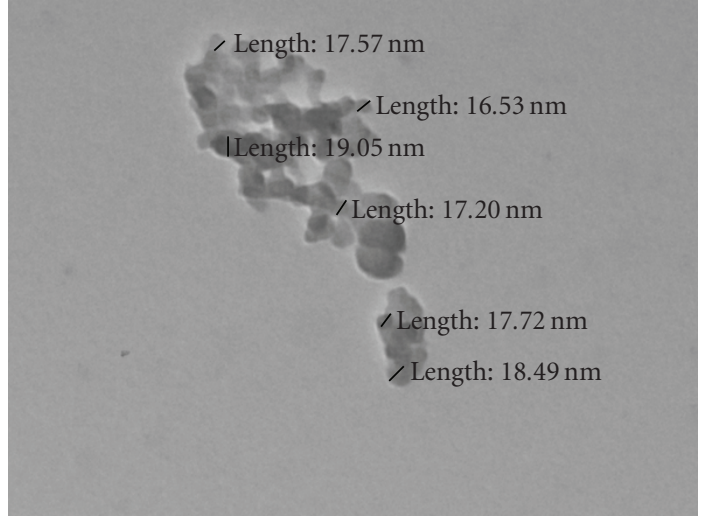

(b)

Figure 3: TEM images of (a) Acrylate matrix (without metal dispersion) (b) Acrylate matrix (with metal dispersion). The images confirm the dispersion of particles of size $<20 \mathrm{~nm}$.

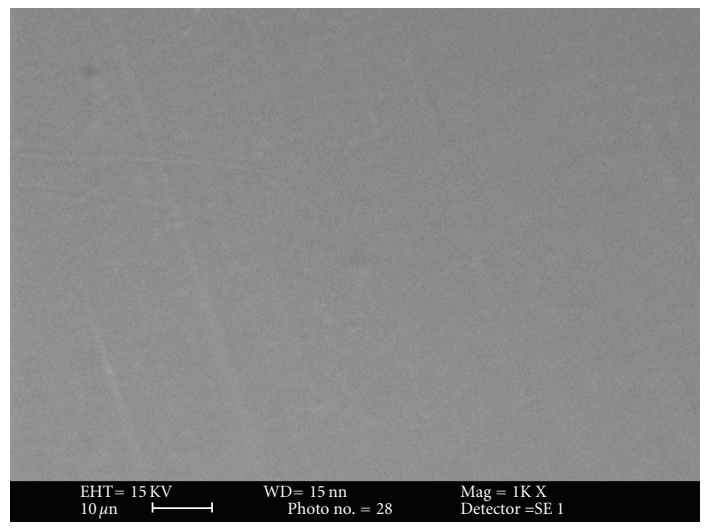

(a)

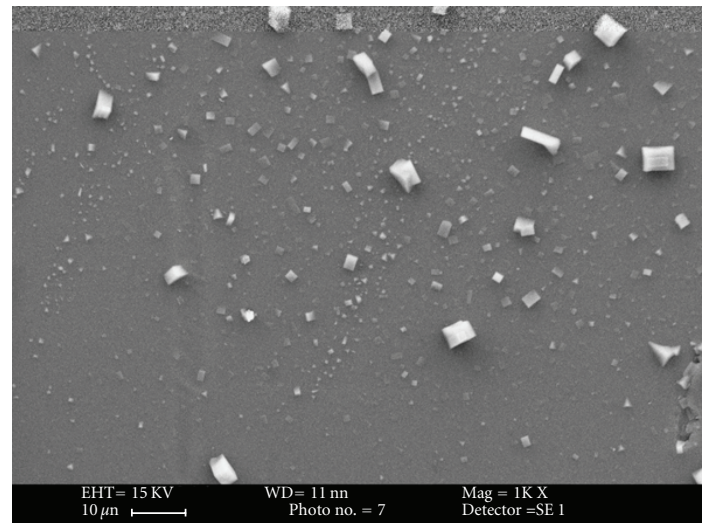

(b)

Figure 4: SEM images of (a) Acrylate matrix (without metal dispersion), (b) Acrylate matrix (with metal dispersion). The images confirm the presence of nanoparticles in the polymer matrix.

(7) Inductively Coupled Plasma (ICP). Inductively Coupled Plasma technique was used to determine the amount of titanium present in the matrix. The studies were carried out using ICP-OES (VISTA-MPX EL06033904) of Varian Instruments, Australia.

(8) Ash Content. Muffle furnace maintained at $600^{\circ} \mathrm{C}$ was used for evaluating the ash content of metal containing polymers. The residue was then weighed and ash percentage was calculated using the following formula:

$$
\operatorname{Ash}(\%)=\frac{\left(\mathrm{W}_{3}-\mathrm{W}_{1}\right)}{\left(\mathrm{W}_{2}-\mathrm{W}_{1}\right)} \times 100
$$

where $\mathrm{W}_{1}=$ weight of empty crucible, $\mathrm{W}_{2}=$ weight of crucible + sample, and $\mathrm{W}_{3}=$ weight of ash + crucible (after heating).

\section{Results and Discussion}

(1) FTIR Analysis. FTIR spectra (Figure 1) of acrylatetitanium composite confirms the formation of titaniumacrylates.

The stretching vibration bands at 1730 and $2950 \mathrm{~cm}^{-1}$ are ascribed to $\mathrm{C}=\mathrm{O}$ and $\mathrm{C}-\mathrm{H}$ bonds, respectively, [16]. The presence of absorption band at $1630 \mathrm{~cm}^{-1}$ is due to $\mathrm{TiO}_{2}$ and a broad absorption band at $3400-3500 \mathrm{~cm}^{-1}$ may be attributed to the $\mathrm{Ti}-\mathrm{OH}$ bond [12]. It can infact, be said that the IR studies confirm the simultaneous formation and dispersion of $\mathrm{TiO}_{2}$ by the formation of intermediates in the acrylate matrix during the dispersion of the titanium precursor besides the formation of titanium-acrylate monomer. The mechanism is described (2)

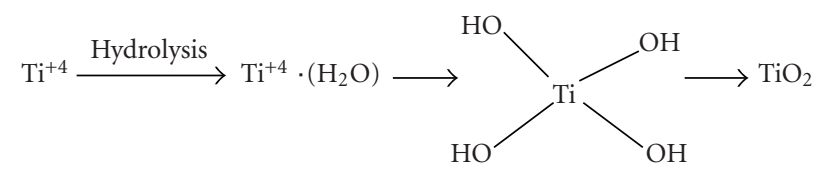




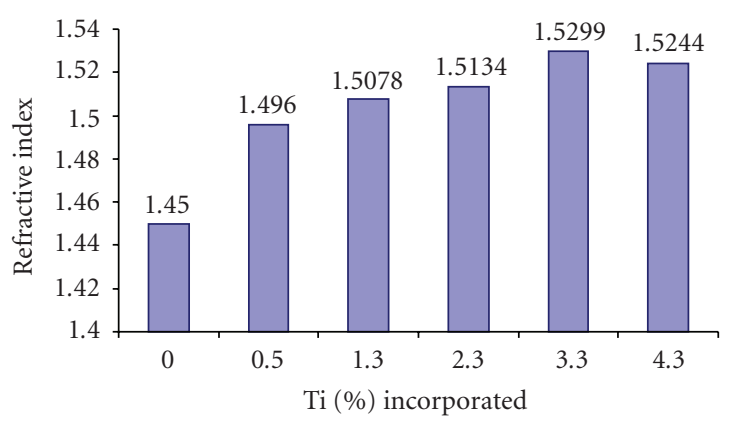

(a)

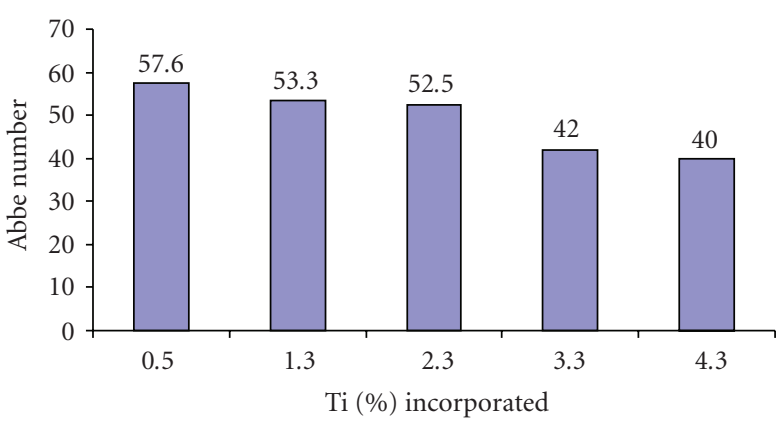

(b)

FIGURE 5: (a) Refractive index increases with increase in titanium content and (b) Abbe number decreases with increase in titanium content.

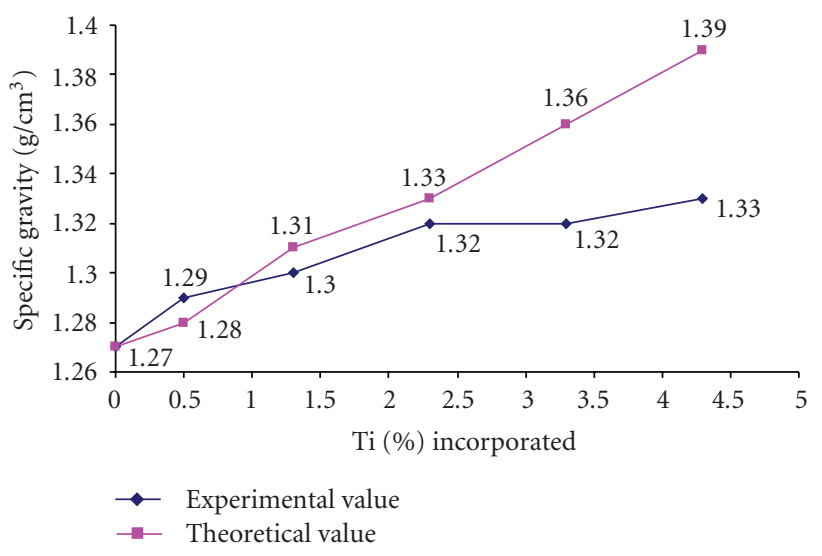

FIGURE 6: Specific gravity of the polymer increases with increase in titanium content.

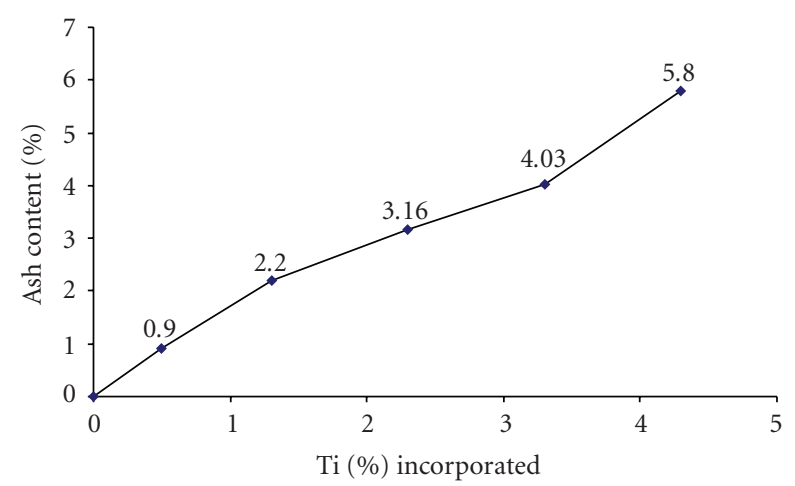

FIGURE 7: Ash content increases with increase in titanium content confirming the dispersion of titanium in the acrylate matrix.

(2) Thermal Analysis. TGA analysis shows the thermal stability of the acrylate polymer and metal containing polymers. The TGA graphs in Figure 2 shows that the neat polymer decomposes completely without any residue at $\sim 500^{\circ} \mathrm{C}$ while the metal dispersed polymer shows a residual content of $\sim 5 \%$ in (a) and $10 \%$ in (b).

The thermal stability of metal dispersed polymer is increased significantly as the content of the metal increases; the initial decomposition of the polyacrylate matrix without dispersion is at $120^{\circ} \mathrm{C}$ which increases to $\sim 220^{\circ} \mathrm{C}$ in the case of $0.5 \%$ dispersion of titanium (a) and to $\sim 240^{\circ} \mathrm{C}$ in the case of $4.3 \%$ dispersion of titanium (b).

(3) TEM and SEM Analysis. TEM images indicate a particle size $<20 \mathrm{~nm}$ as shown in Figure 3(a) and 3(b).

The SEM images (Figure 4) confirms the shape of titanium particles to be cuboidal. The lenses were evaluated through polariscope and were found to be bubble free.

(4) Refractive Index and Abbe Number. The effect of titanium content on the refractive index of the acrylate matrix can be understood from Figure 5(a). As the incorporation of titanium in the acrylate matrix increases, the refractive index increases from 1.45 to 1.53 . The effect of incorporation of titanium in the acrylate monomer on Abbe number can be seen from Figure 5(b). The Abbe number decreases from 57 to 40 .

(5) Transmittance (\%). Titanium containing acrylates were found to be clear and transparent having a transmittance of more than $90 \%$. This confirms the formation of transparent and clear compositions due to the dispersion of nanoparticles in the acrylate matrix.

(6) Specific Gravity. Specific gravity of the titanium containing polyacrylates is depicted in Figure 6. The specific gravity of the samples increases with the increase in the titanium content. Even though titanium is a heavy metal of specific gravity of $4.54 \mathrm{~g} / \mathrm{cm}^{3}$, the specific gravity of the polymers is in the range of 1.29 to 1.33 which is similar to the specific gravity of optical polymers such as Polycarbonate (1.28), Polymethyl Methacrylate (1.26) and Polythiourethane (1.36) which supports the fact that metal composites are suitable for optical applications.

(7) Inductively Coupled Plasma (ICP). ICP analysis was carried out to determine the percentage dispersion of titanium in the metal containing polymers. The ICP results are found to agree closely with the theoretical value and falls in the range of $0.5 \%$ to $4.3 \%$ by wt. 
(8) Ash Content. Ash content of the sample as evaluated from the furnace studies was used to indicate the residue (\%) of the metal containing polymer. The polymer was burnt to ash and the residue (\%) was calculated. The graph in Figure 7 shows the increase in ash content (\%) with increase in content of titanium.

\section{Conclusions}

From the above studies, the following conclusions can be drawn:

(1) Metal containing polyacrylates with improved refractive index and desired Abbe number suitable for optical applications have been developed successfully.

(2) Microscopy studies indicate the formation of transparent and clear nanocomposites where the refractive index and Abbe number can be tailor made between $1.45-1.53$ and $40-57$, respectively.

(3) Novel nanocomposites of polyacrylates have been developed for the first time which paves the way for the use of hybrid materials for high refractive index applications.

\section{Acknowledgments}

The authors wish to express their sincere thanks to the Management of Shriram Institute for Industrial Research, India, for guidance and support. The authors also thank Department of Science \& Technology, India for sponsoring the work.

\section{References}

[1] M. Tyagi, M. Verma, G. Seshadri, A. Malik, S. Agarwal, and R. K. Khandal, "Development of metal containing polymers for optical application," Journal of Polymer Materials, vol. 23, no. 1, pp. 21-28, 2006.

[2] H. Dislich, "Plastics as optical materials," Angewandte Chemie International Edition, vol. 18, no. 1, pp. 49-59, 1979.

[3] M. Tyagi, G. S. Jha, G. Seshadri, A. Malik, S. Aggarwal, and R. K. Khandal, "Metal containing polymers for optical applications; part II," Journal of Polymer Materials, vol. 24, no. 2, pp. 135-148, 2007.

[4] J. D. Lytle, Handbook of Optics, McGraw Hill, New York, NY, USA, 2nd edition, 1995.

[5] W. F. Frank, "Precision plastics optics for optical storage," in Precision Plastic Optics for Optical Storage, Displays, Imaging, and Communications, vol. 3135 of Proceedings of the SPIE, pp. 169-178, July 1997.

[6] M. Verma, G. S. Jha, G. Seshadri, and R. K. Khandal, "Optical plastics - a wonder material," Journal of the Indian Chemical Society, vol. 82, no. 12, pp. 1113-1118, 2005.

[7] G. S. Jha, G. Seshadri, A. Mohan, and R. K. Khandal, "Development of high refractive index plastics," e-polymers, no. 120 , pp. 1-25, 2007.

[8] G. Philipp and H. Schmidt, "New materials for contact lenses prepared from Si- and Ti-alkoxides by the sol-gel process," Journal of Non-Crystalline Solids, vol. 63, no. 1-2, pp. 283-292, 1984.
[9] B. Wang, G. L. Wilkes, J. C. Hedrick, S. C. Liptak, and J. E. McGrath, "New high refractive index organic/inorganic hybrid materials from sol-gel processing," Macromolecules, vol. 24, no. 11, pp. 3449-3450, 1991.

[10] F. Papadimitrakopoulos, P. Wisniecki, and D. E. Bhagwagar, "Mechanically attrited silicon for high refractive index nanocomposites," Chemistry of Materials, vol. 9, no. 12, pp. 2928-2933, 1997.

[11] A. Ershad-Langroudi, C. Mai, G. Vigier, and R. Vassoille, "Hydrophobic hybrid inorganic-organic thin film prepared by sol-gel process for glass protection and strengthening applications," Journal of Applied Polymer Science, vol. 65, no. 12, pp. 2387-2393, 1997.

[12] W. C. Chen, S. J. Lee, L. H. Lee, and J. L. Lin, "Synthesis and characterization of trialkoxysilane-capped poly(methyl methacrylate)-titania hybrid optical thin films," Journal of Materials Chemistry, vol. 9, no. 12, pp. 2999-3004, 1999.

[13] H. A. Hornak, Polymers for Lightwave and Integrated Optics, Marcel Dekker, New York, NY, USA, 1992.

[14] "American Standard Test Method for Index of Refraction of Transparent Organic Plastics ASTM D-542," 2009.

[15] "American Standard Test Method for density and specific gravity (Relative density) of plastics by displacement ASTM D-792-00," 1995.

[16] A. Leaustic, F. Babonneau, and J. Livage, "Structural investigation of the hydrolysis-condensation process of titanium alkoxides $\mathrm{Ti}(\mathrm{OR})_{4}(\mathrm{OR}=\mathrm{OPri}, \mathrm{OEt})$ modified by acetylacetone. 1 . Study of the alkoxide modification," Chemistry of Materials, vol. 1, no. 2, pp. 240-247, 1989. 

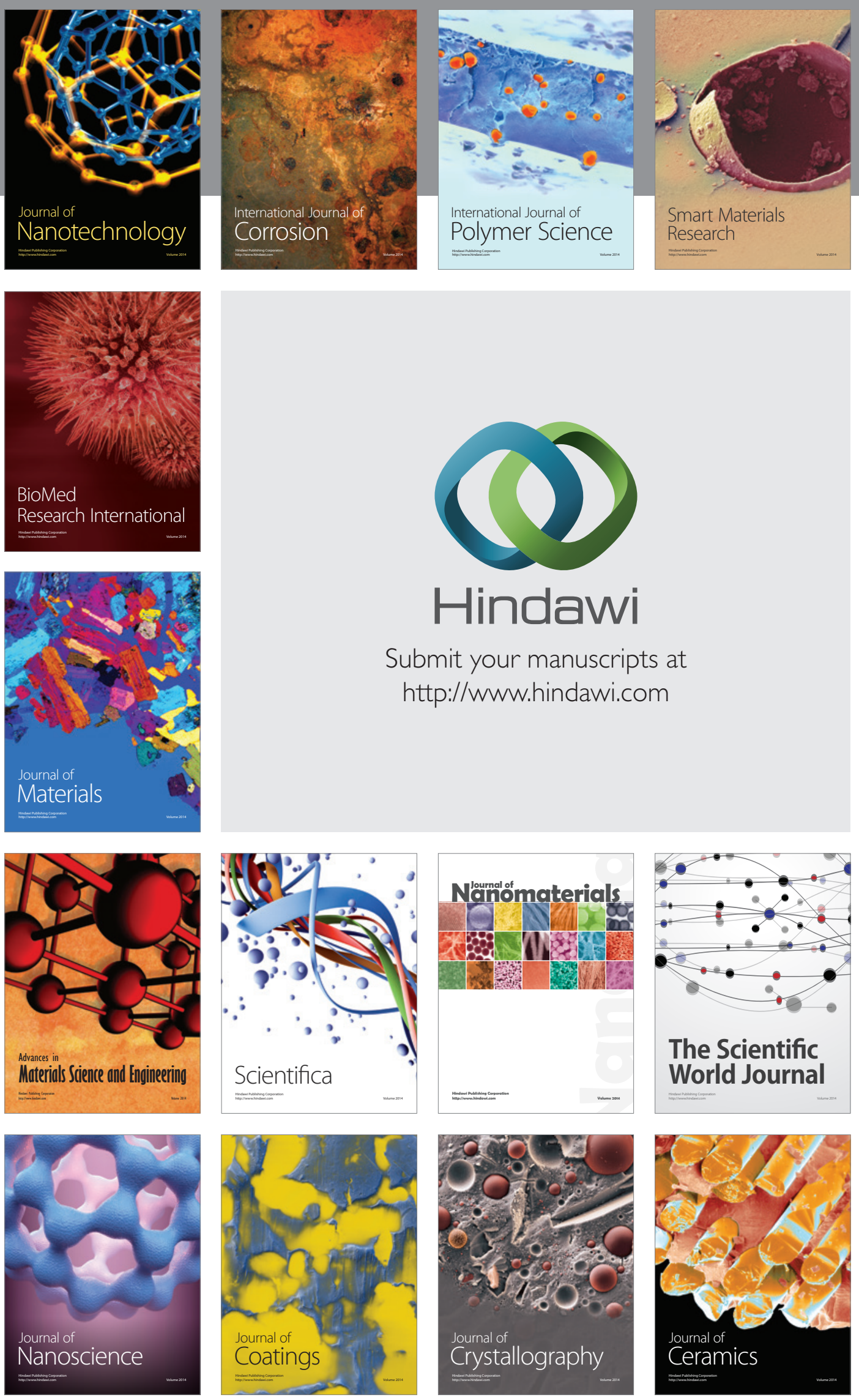

The Scientific World Journal

Submit your manuscripts at

http://www.hindawi.com

\section{World Journal}

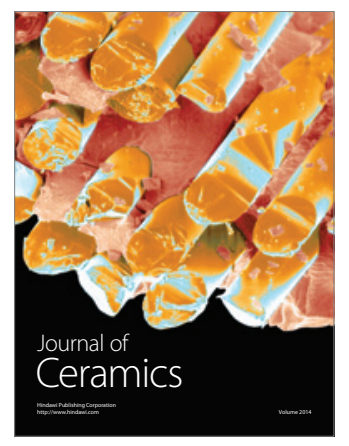

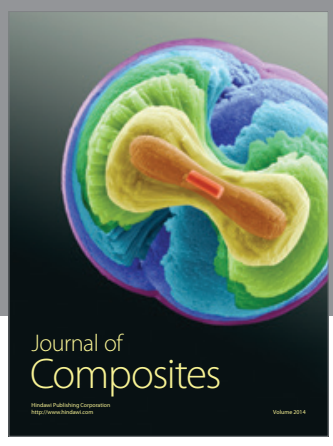
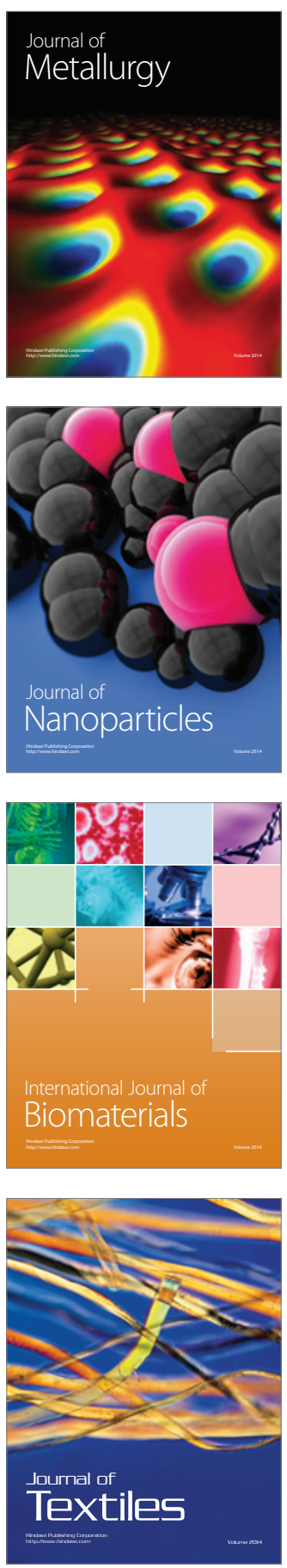